\title{
Polymorphonuclear Neutrophil Dysfunctions in Streptozotocin-induced Type 1 Diabetic Rats
}

\author{
A.H.M. Nurun Nabi ${ }^{\dagger}{ }^{\S} *$, Laila N. Islam ${ }^{\dagger}$, Mohammad Mahfuzur Rahman and Kazal Boron Biswas ${ }^{\sharp}$ \\ 'Department of Biochemistry and Molecular Biology, University of Dhaka, Dhaka-1000, Bangladesh \\ Bangladesh Institute of Research and Rehabilitation in Diabetes, Endocrine and Metabolic Disorders, Shahbag, Dhaka \\ ${ }^{\S}$ Lab of Animal Biochemistry, Department of Animal Science and Technology, Gifu University, \\ 1-1 Yanagido, 501-1193, Gifu Shi, Gifu, Japan
}

Received 30 June 2005, Accepted 19 August 2005

Since conflicting results have been reported on non-specific immune response in type 1 diabetes, this study evaluates polymorphonuclear neutrophil (PMN) functions in the infection free Long Evan diabetic rats (type 1) by using tests that include: polarization assay, phagocytosis of baker's yeasts (Saccharomyces cerevisiae) and nitroblue tetrazolium (NBT) dye reduction. Polarization assay showed that neutrophils from diabetic rats were significantly activated at the basal level compared to those from the controls $(p<0.001)$. After PMN activation with $\mathrm{N}$-formylmethionyl-leucyl-phenylalanine (FMLP), control neutrophils were found to be more polarized than those of the diabetic neutrophils and the highest proportions of polarization were found to be $67 \%$ and $57 \%$ at $10^{-7} \mathrm{M}$ FMLP, respectively. In the resting state, neutrophils from the diabetic rats reduced significantly more NBT dye than that of the controls $(p<0.001)$. The percentages of phagocytosis of opsonized yeast cells by the neutrophils from control and diabetic rats were $87 \%$ and $61 \%$, respectively and the difference was statistically significant $(p<0.001)$. Evaluation of the phagocytic efficiency of PMNs revealed that control neutrophils could phagocytose $381 \pm 17$ whereas those from the diabetic rats phagocytosed $282 \pm 16$ yeast cells, and the efficiency of phagocytosis varied significantly $(p<$ 0.001). Further, both the percentages of phagocytosis and the efficiency of phagocytosis by the diabetic neutrophils were inversely related with the levels of their corresponding plasma glucose $(p=0.02 ; r=-0.498$ and $p<0.05 ; r=-0.43$, respectively), which indicated that increased plasma glucose reduced the phagocytic ability of neutrophils. Such relationship was not observed with the control neutrophils. These data clearly indicate that PMN functions are altered

\footnotetext{
* To whom correspondence should be addressed.

Tel: \& Fax: 81-58-239-2868

E-mail: nurunnabi369@yahoo.com
}

in the streptozotocin (STZ) - induced diabetic rats, and hyperglycemia may be the cause for the impairment of their functions leading to many infectious episodes.

Keywords: NBT dye reduction, Phagocytosis, Polarization, Rat neutrophils, Type 1 diabetes,

\section{Introduction}

Diabetes related complications are reflected in the host defense mechanisms from the non-specific to specific immune systems. Neutrophils, being the member of the non-specific immune system, play a critical role in the host defense mechanism against various bacterial infections and it is suggested that the impaired neutrophil functions [e.g., chemotaxis, phagocytosis, nitroblue tetrazolium (NBT) dye reduction ability etc.] are factors that cause the susceptibility to infections in diabetics (Coopan, 1985; Reeves and Wilson, 1992). However, the opinions concerning the incidence of infections in diabetes are divergent. Some authors claim that susceptibility to infections increased markedly, while others believe that susceptibility to infections is not exaggerated in diabetic patients managed appropriately and in good control (Dziatkowiak et al., 1982). But, most investigators agree that there is an increase in severity of infections in poorly controlled diabetes.

One of the major causes of diabetes related complications is hyperglycemia but the exact mechanism of its detrimental effects is not clear. Hyperglycemic patients remain persistently at risk for infectious complications (Hostetter, 1990). Investigators have evaluated that polymorphonuclear neutrophil (PMN) functions especially phagocytosis and bactericidal activity are impaired in type 1 diabetes mellitus (Marhoffer et al., 1992; Marhoffer et al., 1993; Gallacher et al., 1995) and this 
impairment is related with the metabolic control of the study subjects, and it seems that bactericidal function improves as the blood glucose control improves (Gallacher et al., 1995). Some researchers have shown that although PMN phagocytosis occurs at similar levels in diabetics and controls, but the killing of the E. coli and Candida are impaired (Wilson and Reeves, 1986; Islam et al., 2000). On the contrary, another group claimed that type 1 diabetic subjects are characterized by a significant impairment of phagocytic capacity when compared with healthy donors (Serlenga et al., 1993).

Many studies have demonstrated an impaired production of oxygen-derived free radicals [e.g., superoxide anions $\left(\mathrm{O}^{-2}\right)$ and hydrogen peroxide-myeloperoxidase-halide $\left(\mathrm{H}_{2} \mathrm{O}_{2}\right.$-MPO$\mathrm{Cl}^{-}$) anti microbial system] by neutrophils from poorly controlled diabetic patients and STZ-induced diabetic rats (Shah et al., 1983; Sato et al., 1992; Sato et al., 1992; Sato et al., 1993). PMNs from type 1 diabetic subjects showed a highly significant reduction in chemiluminescence response when stimulated (Marhoffer et al., 1992). Also, neutrophils from poorly controlled insulin-dependent diabetics showed impaired ability to generate oxygen radicals $\left(\mathrm{O}^{-2}\right)$ in response to FMLP, and it was solely attributed to the high glucose concentration (Ortmeyer and Mohsenin, 1996). However, contradictory reports are available on the ability of unstimulated diabetic neutrophils to reduce more NBT dye compared to the control cells, both at their basal level (Csato et al., 1980; Weirusz-Wysocka et al., 1987).

Although several studies have been carried out to resolve the controversial non-specific immune responses in type 1diabetes, inexplicable controversies with regard to possible functional defects of polymorphonuclear neutrophil leukocytes (PMNs) still persist. Thus, our present study tries to assess the morphological polarization of neutrophils as a marker of their early activation, phagocytosis of opsonized yeast particles, and NBT dye reduction ability for the late activation of these cells in streptozotocin (STZ) - induced type 1 diabetes using Long Evan diabetic model rats.

\section{Materials and methods}

Animals A total of 30 Long Evan rats (Male: 15; Female: 15) each 2 weeks of age were purchased from the Animal Resources Division of the International Center for Diarrheal Disease Research, Bangladesh. The animals were kept in the plastic cages with even floors covered with wood shavings in the animal house of the department of Biochemistry and Molecular Biology, University of Dhaka, Bangladesh. The initial average body weight of the male rats was $145 \pm 6 \mathrm{gm}$ and of the female rats was $141 \pm 4 \mathrm{gm}$. These animals were kept under constant temperature with a 14 hour light and 10 hour dark cycle. About 5-6 gm of balanced pelleted rat food was supplied thrice a day. The animals had also free access to drinking water. These conditions were maintained for the next 4 weeks.

Preparation for streptozotocin-induced type 1 diabetes in the rats Rats were randomly assigned into two experimental groups: control group consisted of 5 male and 5 female rats and the diabetic group consisted of 10 male and 10 female rats. Diabetes was induced at the age of 6 weeks $(186 \pm 10$ gm and $181 \pm 11$ gm body weights for male and female rats, respectively) by an intraperitoneal injection of streptozotocin (STZ) dissolved in citrate buffer $(65 \mathrm{mg} /$ $\mathrm{Kg}$ body weight). Age matched control rats were injected with citrate buffer only. The development of diabetes was confirmed by the presence of hyperglycemia (blood glucose level $>230 \mathrm{mg} / \mathrm{dL}$ ). Plasma glucose levels were determined by the glucose oxidase method using blood samples obtained from the animal tail. The rats were used for the experiments 1 week after receiving STZ injection.

Collection of blood and plasma After completion of the experimental protocols, blood samples were collected by sacrificing each diabetic and control rats. The animals were anesthetized in a chamber containing diethyl ether. Blood was collected into a heparincontaining container. Immediately after collection, $2.0 \mathrm{ml}$ of blood was transferred into fresh tube and centrifuged at $3000 \mathrm{rpm}$ for 10 minutes. The plasma was collected and stored at $-20^{\circ} \mathrm{C}$ until further analysis.

Isolation of neutrophils Neutrophils were isolated from the freshly collected blood samples of control and diabetic rats by the standard procedure of dextran (Sigma, St. Louis, USA) sedimentation followed by centrifugation on Ficoll-Hypaue (Pharmacia, Uppsala, Sweden). Neutrophils were washed twice with Hank's Balanced Salt Solution (HBSS, Sigma) containing $10 \mathrm{mM}$ 3-(N-morpholino)propanesulfonic acid (MOPS, Sigma). Hypotonic shock was used for the removal of the remaining red blood cells from the white cell preparation. This cell preparation consisted of more than $95 \%$ neutrophils with the remainder being mostly eosinophils and basophils (Shields and Haston, 1985). The separated neutrophils were resuspended in 1.0-2.0 $\mathrm{ml}$ of HBSS-MOPS, immediately counted, and then diluted with the medium according to the different experimental needs.

Polarization assay Polarization assay of neutrophils was performed by using different concentrations (ranging from $10^{-9}-10^{-5} \mathrm{M}$ ) of a chemotactic factor, N-formyl-methionyl-leucyl-phenylalanine (FMLP). Neutrophils $\left(1 \times 10^{6}\right.$ cells $\left./ \mathrm{ml}\right)$ were taken into different conical based sterile tubes (Fisher Scientific, Pittsburg, USA) and different concentrations of FMLP were added to the cells. The cells were incubated for 30 minutes at $37^{\circ} \mathrm{C}$ and then fixed with $2 \%(\mathrm{v} / \mathrm{v})$ glutaraldehyde (Sigma), washed twice with excess of HBSSMOPS. The percentage of polarized cells was assessed by viewing the cell preparation under Light microscope using a 40X objective (Nabi and Islam, 2001). At least 300 cells were counted from each preparation.

NBT dye reduction assay Neutrophils $\left(2 \times 10^{6}\right.$ cells $\left./ \mathrm{ml}\right)$ from control and diabetic rats were taken in two separate glass tubes and fresh control plasma was added into the cells. The rest of the procedure was as described elsewhere (Nabi and Islam, 2001). Briefly, the cells were incubated for 30 minutes at $37^{\circ} \mathrm{C}$ and then aliquots of NBT (Sigma) solution was added into the cells and incubated for 1 hour at $37^{\circ} \mathrm{C}$. The unused NBT was removed through washing and the reduced dye was extracted in dioxan (Sigma) and quantitated at $520 \mathrm{~nm}$. 
Phagocytosis assay For the phagocytosis assay, opsonized baker's yeasts (Saccharomyces cerevisiae; Gist brocades, Holland) were prepared by preincubating with fresh control serum and washed, while unopsonized yeasts were only washed with the HBSSMOPS. To perform the assay, neutrophils $\left(1 \times 10^{6}\right.$ cells $\left./ \mathrm{ml}\right)$ were used from both the control and diabetic rats. Two drops of neutrophils in HBSS-MOPS were taken onto clean glass slides and incubated for 5 minutes at $37^{\circ} \mathrm{C}$. A few drops of prepared yeasts at $1 \times 10^{8} / \mathrm{mL}$ were then added to the neutrophils and incubated for a further 5 minutes at $37^{\circ} \mathrm{C}$. The rest of the procedure and the scoring were done as described previously (Islam and Nabi, 2003). Briefly, neutrophils with three or more attached yeasts were scored as phagocytic cells. However, this method did not distinguish between engulfed yeast and those which were attached to the cell surface. The percentage of phagocytic cells and the number of yeast cells attached per 100 randomly chosen neutrophils were counted by examining at least 300 neutrophils from each preparation (controls and diabetics) under the oil immersion lens.

Statistical analyses The results were expressed as mean \pm SD. To compare the differences between neutrophils from the control and diabetic rats, independent Student's $t$-test was performed. Correlation was determined by using non-parametric Spearman's rho test. A $p$ value of less than 0.05 was considered significant.

\section{Results}

Polarization of neutrophils Different concentrations of FMLP ranging from $10^{-9}$ to $10^{-5} \mathrm{M}$ were used to observe the doseresponse for neutrophil polarization at $37^{\circ} \mathrm{C}$. It was found that there were differences in the proportions of polarized cells at each dose of FMLP. The results using neutrophils from diabetic $(n=18)$ and control rats $(n=10)$ are shown in Fig. 1 . The maximum percentages of polarized cells, about $67 \%$ (for controls) and $57 \%$ (for diabetics), were obtained at $10^{-7} \mathrm{M}$ FMLP. Neutrophils from both the groups were found less polarized at higher concentrations of FMLP, $10^{-5} \mathrm{M}$ or $10^{-6} \mathrm{M}$. However, neutrophils from diabetic rats were significantly more polarized $(p<0.001)$ at the baseline level (without added FMLP) compared to those from control rats $(30 \pm 4$ vs $13 \pm 3)$. Moreover, the proportion of polarized cells from the diabetic rats did not show any significant difference compared to those from the control rats when stimulated with the higher concentrations of FMLP $\left(10^{-5}\right.$ and $\left.10^{-6} \mathrm{M}\right)$, while at lower concentrations $\left(10^{-7}\right.$ to $\left.10^{-9} \mathrm{M}\right)$ significant differences (at least, $p<0.01$ ) were found.

NBT reduction by neutrophils The mean O.D. value of the reduced NBT dye under the experimental conditions for the neutrophils from diabetic rats was found to be $0.12 \pm 0.03$ while the corresponding value for the control neutrophils was $0.04 \pm 0.01$. Statistical analysis revealed that at the baseline level, neutrophils from diabetic rats could reduce significantly more NBT dye $(p<0.001)$ than those from control rats. Table 1 represents the results of NBT dye reduction by neutrophils from both groups.

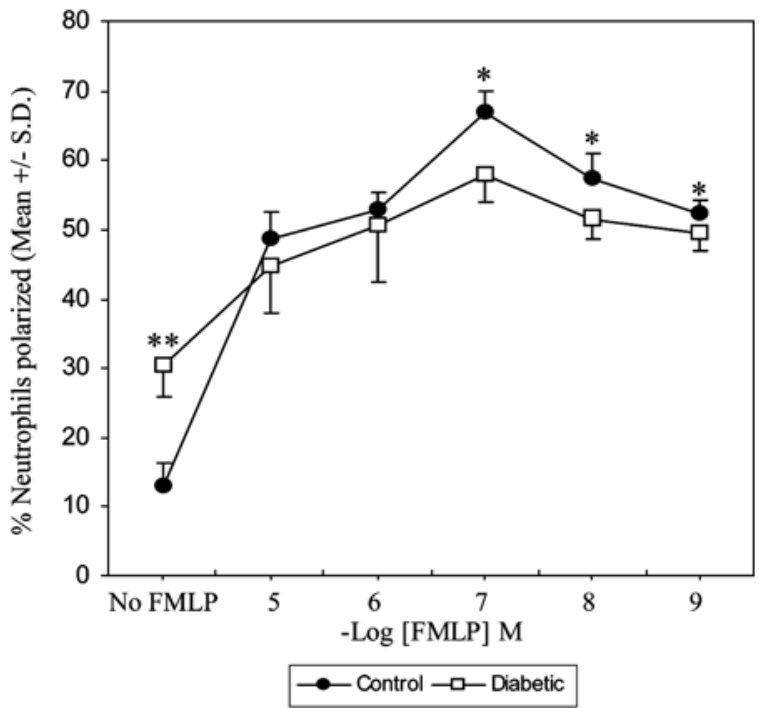

Fig. 1. Percentages of polarized neutrophils from control and diabetic rats toward different concentrations of FMLP $\left(10^{-9}\right.$ to $\left.10^{-5} \mathrm{M}\right)$. The highest proportions of polarized neutrophils were found at $10^{-7} \mathrm{M}$ FMLP. Diabetic neutrophils showed significantly high polarization at the baseline level (denoted as 'No FMLP') compared to their control counterparts $\left({ }^{*} p<0.001\right)$. Neutrophils from diabetic rats showed less polarization compared to those of control rats and the proportions of polarized cells varied significantly $(* p<0.01)$.

Phagocytosis by the diabetic and control neutrophils Neutrophils from both the groups of rats were allowed to phagocytose opsonized yeast cells. The percentages of neutrophils phagocytosing opsonized yeasts were found to be $87 \pm 4 \%$ and $61 \pm 7 \%$ by the control and diabetic rats, respectively. Statistical analysis showed neutrophils from the diabetic rats were less phagocytic than those from the control rats $(p<0.001)$. The results have been documented in Table 1 . To test the nonopsonic phagocytic activity, neutrophils from both groups of rats were allowed to phagocytose unopsonized yeast cells. Table 1 shows that compared to $32 \pm 4 \%$ of the control neutrophils, $21 \pm 4 \%$ of the diabetic neutrophils phagocytosed unopsonized yeast cells. Neutrophils from the diabetic rats were found less phagocytic to unopsonized yeasts $(p<0.001)$.

Efficiency of phagocytosis by the neutrophils from control and diabetic rats Data of the present study revealed that neutrophils from diabetic and control rats could not phagocytose the same number of yeast cells. The percentages of neutrophils from both groups that had phagocytosed 3-6, 710 and more than 10 opsonized yeasts have been shown in Fig. 2. Neutrophils attached with more than 10 yeasts were considered to be the highly efficient phagocytic cells. The percentages of highly efficient neutrophils phagocytosing opsonized yeasts were about $11 \pm 1 \%$ and $6 \pm 2 \%$ for the control and diabetic groups, respectively. On the other hand, the percentages of highly efficient neutrophils phagocytosing 
Table 1. Phagocytosis and NBT dye reduction by neutrophils from control and diabetic rats

\begin{tabular}{cccccc}
\hline \multirow{2}{*}{ Neutrophils } & $\begin{array}{c}\text { \% Neutrophils } \\
\text { phagocytosing } \\
\text { opsonized yeasts }\end{array}$ & $\begin{array}{c}\text { No. of opsonized } \\
\text { yeasts attached } \\
\text { to } 100 \text { neutrophils }\end{array}$ & $\begin{array}{c}\text { \% Neutrophils } \\
\text { phagocytosing unop- } \\
\text { sonized yeasts }\end{array}$ & $\begin{array}{c}\text { No. of unopsonized } \\
\text { yeasts attached to 100 } \\
\text { neutrophils }\end{array}$ & $\begin{array}{c}\text { Reduced NBT } \\
\text { dye in dioxan, } \\
\text { O.D. at 520 nm }\end{array}$ \\
\cline { 2 - 7 } Control & $\begin{array}{c}\text { Mean } \pm \text { SD } \\
\text { (Range) }\end{array}$ & $\begin{array}{c}\text { Mean } \pm \text { SD } \\
\text { (Range) }\end{array}$ & $\begin{array}{c}\text { Mean } \pm \text { SD } \\
\text { (Range) }\end{array}$ & $\begin{array}{c}\text { Mean } \pm \text { SD } \\
\text { (Range) }\end{array}$ & $\begin{array}{c}\text { Mean } \pm \text { SD } \\
\text { (Range) }\end{array}$ \\
\hline \multirow{2}{*}{ Diabetic } & $(80-94)$ & $381 \pm 17$ & $32 \pm 4$ & $240 \pm 12$ & $0.04 \pm 0.01$ \\
& $(48-70)$ & $282 \pm 16$ & $(25-37)$ & $(224-265)$ & $(0.02-0.06)$ \\
\hline$p$ values & $<0.001$ & $(210-310)$ & $(15-30)$ & $(133-198)$ & $0.12 \pm 0.03$ \\
\hline
\end{tabular}

In the phagocytosis assays, the numbers of experiments were 10 and 20, using neutrophils from 10 control and 20 diabetic rats, respectively. In the NBT test, the numbers of experiments were 7 for control rats and 12 for diabetic rats.

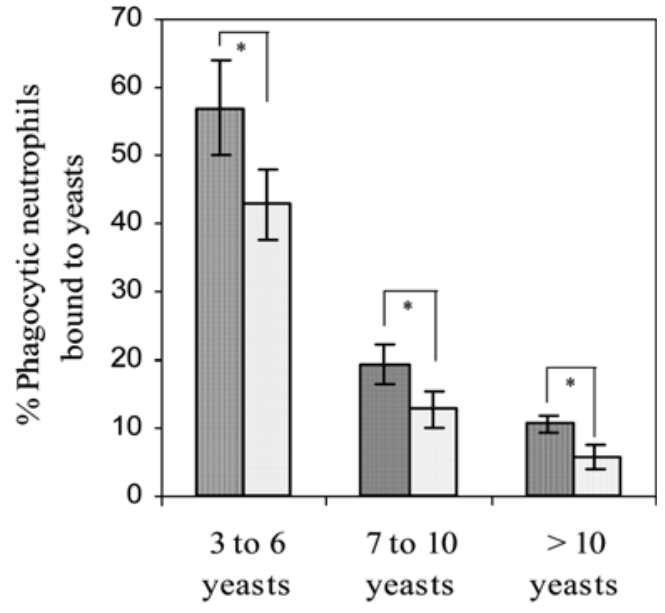

$\square$ Controls $\square$ Diabetics

Fig. 2. Percentages of neutrophils from the control and diabetic rats phagocytosing 3-6, 7-10 and more than 10 opsonized yeasts. The number of yeasts attached to neutrophils varied significantly between control and diabetic rats $(p=<0.001)$. $n=20$ and 10 for diabetic and control rats, respectively.

unopsonized yeasts were found $4 \pm 1 \%$ and $2 \pm 2 \%$ for the control and diabetic rats, respectively. The differences were found significant $(p<0.001$ and $p<0.01)$, for neutrophils phagocytosing opsonized and unopsonized yeasts, respectively.

\section{Relationship between plasma glucose level and phagocytic} activity of neutrophils The percentages of phagocytic neutrophils from diabetic rats showed a significant negative relationship $(p=0.02, \mathrm{r}=-0.498)$ with the plasma glucose level of the corresponding rats (Fig. 3), while the control rats did not show such relationship. Furthermore as shown in Fig. 4, diabetic neutrophils phagocytosing the total number of opsonized yeast cells were inversely related to the plasma glucose level $(p<0.05 ; \mathrm{r}=-0.43)$. It clearly demonstrates that increased plasma glucose level can reduce the phagocytic

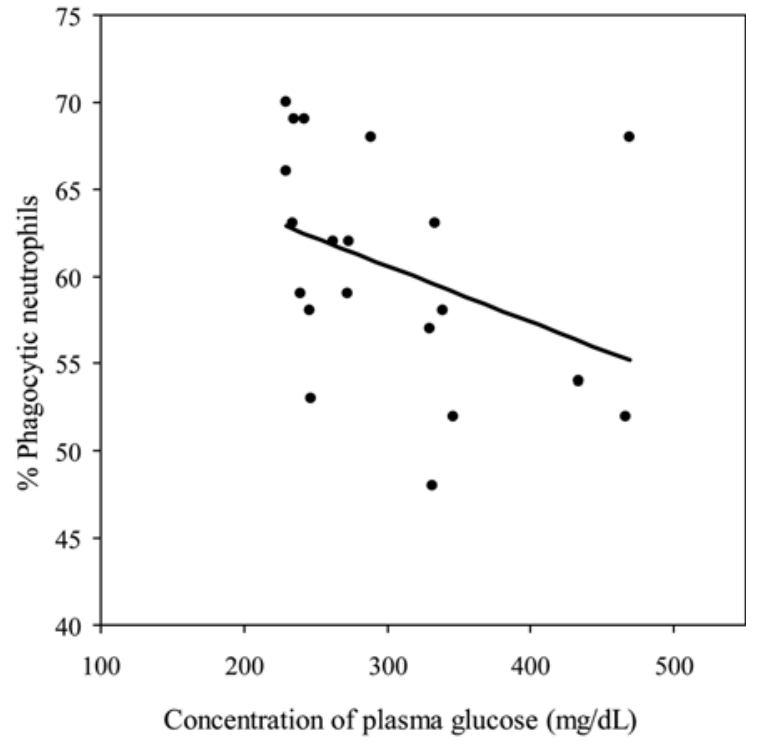

Fig. 3. Relationship between fasting plasma glucose and percentages of phagocytic neutrophils toward opsonized yeasts. The figure demonstrates, phagocytosis by diabetic neutrophils is inversely related to the corresponding plasma glucose level $(p=$ $0.02, \mathrm{r}=-0.498, \mathrm{n}=20$ ).

ability of the neutrophils. Although nonopsonic phagocytosis by the diabetic and control neutrophils revealed significant differences, no relationship was found between the percentage of phagocytic cells and the levels of plasma glucose.

\section{Discussion}

In this study we observed the altered non-specific immune response in STZ-induced diabetic rats by examining different functions of neutrophils such as polarization response to chemotactic factor FMLP, phagocytic capacity and NBT dye reduction ability. It has already been established that diabetic subjects are more prone to infectious diseases compare to their 


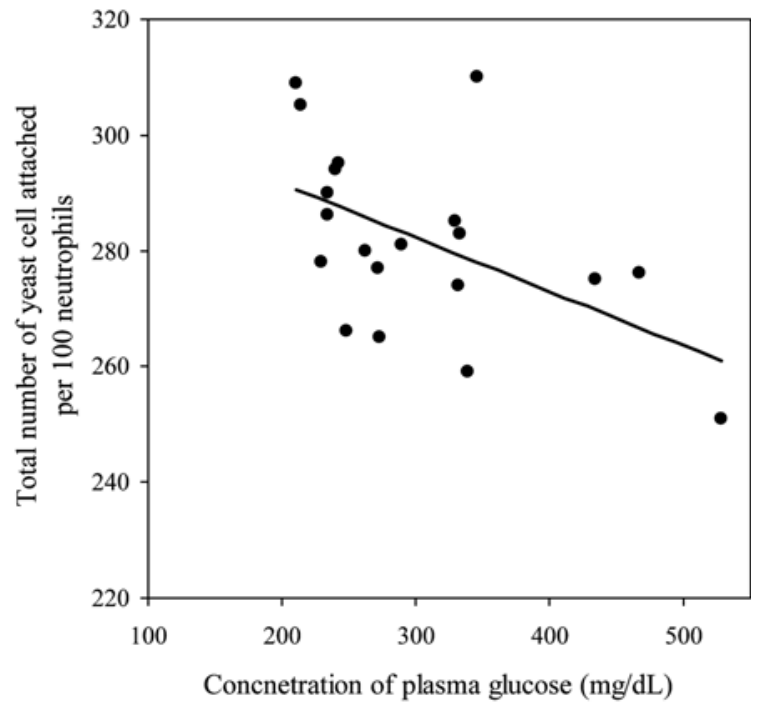

Fig. 4. Relationship between fasting plasma glucose and the total number of opsonized yeasts attached to neutrophils. Each experiment represents the average value of the number of yeasts attached to 100 neutrophils. This figure indicates that high levels of plasma glucose reduces the ability to engulf/adhere opsonized yeast by the neutrophils $(\mathrm{r}=-0.43, p<0.05, \mathrm{n}=20)$.

healthy counterparts. In search for the roles of neutrophils in the pathogenesis of diabetic complications many studies on the functions of neutrophils have been carried out and ended with many controversies.

Polarization assay has been carried out to observe the pattern of early activation of human leukocytes as it is a recognized measure of the early events of locomotion in neutrophils (Shields and Haston, 1985) and monocytes (Islam and Wilkinson, 1988). It was observed that although neutrophils from diabetic rats were found significantly more activated at their basal level, they showed slightly lower morphological polarization in response to FMLP as compared with those from the controls. These data indicate that due to increased blood glucose level, diabetic neutrophils are found activated at the resting state and could not show their normal response toward chemotactic factor. Moreover, microscopic observations revealed that neutrophils from diabetic rats when treated with FMLP showed reduced locomotor shape (chemotactically induced elongation) compared to those of control cells. Our findings support the data of Oldenborg and Sehlin (1997) who described the in vitro effects of D-glucose on the shape changes in FMLP induced neutrophils and concluded that Dglucose could reduce the FMLP $\left(10^{-8} \mathrm{M}\right)$ induced elongation of neutrophils in a dose dependent manner.

The reduction of the NBT dye is an indirect measure of the bactericidal function of neutrophils as generation of $\mathrm{O}^{-2}$ radicals during phagocytosis reduces the dye. Due to spontaneous adhesion of neutrophils and increased production of free radicals by these cells, increased chemiluminescence at the base line level has been reported in diabetic patients, though upon stimulation, the response was lower compared to the controls (Delamaire et al., 1995). Our data revealed that diabetic neutrophils could reduce more NBT dye at their basal level; in contrast, Csato et al. (1980) found significantly lower reduction of NBT dye in diabetes than in healthy donors irrespective of affliction with other dermatoses. Our findings with polarization assay and NBT dye reduction are similar to those obtained by workers measuring other aspects of neutrophil function (Biswas et al., 1993; Delamaire et al., 1995). We did not find any relationship between the NBT reduction ability of the diabetic neutrophils and the plasma glucose level, and the phagocytic ability of the cells. BellinatiPires et al. (1992) also reported similar results that demonstrated that the ability of neutrophils to reduce NBT dye was not correlated with their bactericidal activity but only the absolute absence of NBT reduction reflected the low bactericidal activity of neutrophils.

The percentages of neutrophils from diabetic rats phagocytosing opsonized yeasts has been found to be significantly lower than those from the control cells (Table 1), which is similar to the findings of Pershel et al. (1994). Also, diabetic neutrophils were significantly less efficient in phagocytosing the total number of yeast cells than those by the control cells. Neutrophils from diabetic rats showed significantly lower performance in phagocytosing nonopsonic yeasts though we did not find any correlation with the level of plasma glucose. The complement receptor CR3 has been described to function as a nonopsonic receptor in macrophages (Ehlers, 2000), which is also expressed by neutrophils (Sengelov, 1995). There are receptors on the surface of neutrophils involved in the nonopsonic binding and phagocytosis of many organisms such as M. kanasii, N. meningitides, P. aeruginosa, Streptococci as well as zymosan (Peyron et al., 2000; Albanyan et al., 2000; Eastabrook et al., 1998; Mahenthiralingam and Speert, 1995). Evidences indicate that CR3 also serves in the nonopsonic recognition of microbes by interacting directly with a wide spectrum of molecules on their surfaces (Hetland et al., 1994; Cywes et al., 1997). Unopsonized yeasts can also bind to these receptors (Ross et al., 1985). Thus, receptors involved in the nonopsonic phagocytosis are also assumed to be impaired in diabetic neutrophils, and as a result, these cells showed reduced phagocytic activity even to nonopsonic yeast cells.

In summary, our results indicate that neutrophils from diabetic rats are already activated at their basal level (showed by polarization and NBT dye reduction studies) whereas the phagocytic activity by the cells was significantly reduced. It remains to be shown whether increased plasma glucose level has a direct effect on C3b- and/or Fc-receptor mediated neutrophil phagocytosis that may hinder the cell surface receptors and/or may be due to desensitization of the cells. Excess glucose in the blood may lead to impairment of normal expression and/or inhibition of signals triggering for pinocytic uptake at the phagocytic site for $\mathrm{Fc} \gamma-\mathrm{R}$ mediated phagocytosis (prerequisite for phagocytosis, Botelho et al., 2002). These assumptions become more supportive by the 
characteristically less response of change in the shape of neutrophils when treated with FMLP and the significantly fewer yeast cells phagocytosed (attached as well as engulfed) by the diabetic neutrophils.

Acknowledgments This work was supported by a research grant from the Center for Advanced Studies and Research in Biological Sciences, University of Dhaka, Bangladesh, and was carried out in the Laboratory of Immunology, Department of Biochemistry and Molecular Biology. We thank Mr. Ashok Kumar Barua and Mr. Mizanur Rahman for their help in the maintenance of the Long Evan rats.

\section{References}

Albanyan, E. A., Vallejo, J. G., Smith, C. W. and Edwards, M. S. (2000) Nonopsonic binding of type III group B Streptococci to human neutrophils induces interleukin- 8 release mediated by the p38 mitogen-activated protein kinase pathway. Infect. Immun. 68, 2053-2060.

Billinati-Pires, R., Carneiro-Sampaio, M. M. and Colletto, G. M. (1992) Functional evaluation of human neutrophils. Is the bactericidal activity correlated with nitroblue tetrazolium reduction? J. Invest. Allergol. Clin. Immunol. 2, 146-153.

Biswas, S. K., Bhewla, A. P., Upadhyay, A. U., George, A. and Nath, N. (1993) Status of nitric oxide free radicals in diabetic neutrophils: effect of diabetic serum factor on the generation of these species in normal neutrophils and their relation to lysosomal degranulation. Indian J. Biochem. Biophys. 30, 193196.

Botelho, R. J., Tapper, H., Furuya, W., Mojdami, D. and Grinstein, S. (2002) FcgR-mediated phagocytosis stimulates localized pinocytosis in human neutrophils. J. Immunol. 169, 4423-4429.

Coopan, R. (1985) Infection and diabetes; in Joslin's Diabetes Mellitus, Marbell L. P., Krall, R. F. and Brandley, A. R. (eds.), pp. 737-747, Williams and Wilkins, Lea \& Febiger, Philadelphia, USA

Csato, M., Dobozy, A. and Simon, N. (1980) Study of phagocytic function with a quantitative nitroblue-tetrazolium (NBT) dye reduction tests in diabetes mellitus. Arch. Dermatol. Res. 268, 283-288.

Cywes, C., Hoppe, H. C., Daffe, M. and Ehlers, M. R. W. (1997) Nonopsonic binding of Mycobacterium tuberculosis to complement receptor type 3 is mediated by capsular polysaccharides and is strain dependent. Infect. Immun. 65, 4258-4266.

Delamaire, M., Maugendre, D., Moreno, M., LeGoff, M. C., Allanic, H. and Genetet, B. (1995) Exploration of the various steps of polymorphonuclear neutrophil function in diabetic patients. J. Mal. Vasc. 20, 107-112.

Dziatkowiak, H., Kowalska, M. and Denys, A. (1982) Phagocytic and bactericidal activity of granulocytes in diabetic children. Diabetes 31, 1041-1043.

Eastabrook, M. M., Zhou, D. and Apicella, M. A. (1998) Nonopsonic phagocytosis of group C Neisseria meningitis by human neutrophils. Infect. Immun. 66, 1028-1036.

Ehlers, M. R. W. (2000) CR3: a general purpose adhesionrecognition receptor essential for innate immunity. Microbes
Infect. 2, 289-294.

Gallacher, S. J., Thomson, G., Fraser, W. D., Fisher, B. M. and Gemmell, C. G. (1995) Neutrophil bactericidal functions in diabetes mellitus: evidence for association with blood glucose control. Diabetic Med. 12, 916-920.

Hetland, G. and Wiker, H. G. (1994) Antigen 85C on Mycobacterium bovis, BCG and M. tuberculosis promotes monocyte-CR3-mediated uptake of microbeads coated with mycobacterial products. Immunology 82, 445-449.

Hostetter, M. K. (1990) handicaps to host defence. Effects of hyperglycemia on C3 and Candida albicans. Diabetes 39, 271275.

Islam, L. N., Islam, K. S., Kabir, E. M., Hossain, M. S., Nabi, A. H. M. N. and Banik, N. G. (2000) Impaired neutrophil functions in diabetes mellitus. Bangladesh J. Biochem. 6, 4559.

Islam, L. N. and Nabi, A. H. M. N. (2003) Endotoxins of Enteric Pathogens Modulate the Functions of Human Neutrophils and Lymphocytes. J. Biochem. Mol. Biol. 36, 565-571

Islam, L. N. and Wilkinson, P. C. (1988) Chemotactic factor induced polarization, receptor redistribution and locomotion of human blood monocytes. Immunology 64, 501-507.

Mahenthiralingam, E. and Speert, D. P. (1995) Nonopsonic phagocytosis of Pseudomonas aeruginosa by macrophages and polymorphonuclear leukocytes requires the presence of bacterial flagellum. Infect. Immun. 63, 4519-4523.

Marhoffer, W., Stein, M., Maeser, E. and Federlin, k. (1992) Impairment of polymorphonuclear leukocyte function and diabetes mellitus. Diabetes Care 15, 256-260.

Marhoffer, W., Stein, M., Schleinkofer, L. and Federlin, k. (1993) Evidence of ex vivo and in vitro impaired neutrophil oxidative burst and phagocytic capacity in type 1 diabetes mellitus. Diabetes Res. Clin. Pract. 19, 183-188.

Nabi, A. H. M. N. and Islam, L. N. (2001) Study of the functions of human neutrophils in response to Klebsiella pneumoniae LPS. Dhaka Univ. J. Biol. Sci. 10, 59-68.

Oldenborg, P. A. and Sehlin, J. (1997) D-glucose but not insulin induces N-formyl-methionyl-leucyl-phenylalanine (fMet-LeuPhe)-induced shape changes in suspended human neutrophils. Biosci. Rep. 17, 475-486.

Ortmeyer, J. and Mohsenin, V. (1996) Inhibition of phospholipase $\mathrm{D}$ and superoxide generation by glucose in diabetic neutrophils. Life Sci. 59, 255-262.

Peyron, P., Bordier, C., N'Diaye, E. and Maridonneau-Parini, I. (2000) Nonopsonic phagocytosis of Mycobacterium kansasii by human neutrophils depends on cholesterol and Is mediated by CR3 associated with glycosylphosphatidylinositol-anchored proteins. J. Immunol. 165, 5186-5191.

Reeves, W. G. and Wilson, R. M. (1992) Infection, immunity and diabetes; in International Textbook of Diabetes Mellitus, Alberti, K. G. M. M., De Fronzo, R. A., Kenn, H. and Zimmet, P. (eds.), p. 1165, John Wiley and Son, New York, USA.

Ross, G. D., Cain, J. A. and Lachmann, P. J. (1985.) Membrane complement receptor type three (CR3) has lectin-like properties analogous to bovine conglutinin and functions as a receptor for zymosan and rabbit erythrocytes as well as receptor for iC $3 b$. J. Immunol. 134, 3307-3315.

Sato, N., Shimizu, H., Suwa, K., Shimomura, Y., Mori, M. and Kobayashi, I. (1992) Myeloperoxidase activity and generation 
of active oxygen species in leukocytes from poorly controlled diabetic patients. Diabetes Care 15, 1050-1052.

Sato, N., Shimizu, H., Suwa, K., Uehara, Y., Shimomura, Y., Kobayashi, I. and Kobayashi, S. (1992) Reduced ability of neutrophils to produce active oxygen species in streptozotocininduced diabetic rats. Exp. Clin. Endocrinol. 99, 31-33.

Sato, N., Kashima, K., Shimizu, H., Uehara, U., Shimomura, S. and Mori, M. (1993) Hypertonic glucose inhibits the production of oxygen-derived free radicals by rat neutrophils. Life Sci. 51, 113-118.

Sengelov, H. (1995) Complement receptors in neutrophils. Crit. Rev. Immunol. 15, 107-131.

Serlenga, E., Garofalo, A. R., De Pergola, G., Ventura, M. T., Tortorella, C. and Antonaci, S. (1993) Polymorphonuclear cellmediated phagocytosis and superoxide anion release in insulindependent diabetes mellitus. Cytobios. 74, 189-195.
Shah, S. V., Wallin, J. D. and Eilen, S. D. (1983) Chemiluminescence and superoxide anion production by leukocytes from diabetic patients. J. Clin. Endocrinol. Metab. 57, 402-409.

Shields, J. M. and Haston, W. S. (1985) Behaviour of neutrophil leukocytes in uniform concentrations of chemotactic factors: contraction waves, cell polarity and persistence. J. Cell Sci. 74, 79-93.

Weirusz-Wysocka, B., Wysocki, H., Siekierka, H., Wykretowicz, A., Szczepanik, A. and Klimas, R. (1987) Evidence of polymorphonuclear neutrophils (PMN) activation in patients with insulin-dependent diabetes mellitus. J. Leukoc. Biol. 42, 519-523.

Wilson, R. M. and Reeves, W. G. (1986) Neutrophil phagocytosis and killing in insulin-dependent diabetes. Clin. Exp. Immunol. 63, 478-484. 